\title{
TOWARDS LOW CARBON SOCIETY: EXPLORING USERS' PERCEPTIONS ON THE SERVICE QUALITY LEVEL PERFORMANCE OF PUBLIC TRANSPORT STAFF IN THE KLANG VALLEY
}

\author{
Khairul Baharein Mohd Noor ${ }^{1}$--- Kamariah Dola ${ }^{2}$ \\ ${ }^{\prime}$ Faculty of Management Technology and Technopreneurship, Universiti Teknikal Malaysia Melaka \\ ${ }^{2}$ Faculty of Design and Architecture, Universiti Putra Malaysia, Serdang, Selangor
}

\begin{abstract}
In the midst of Malaysia to become developed nation by the year 2020, there are many strategies implemented, including to encourage the usage of public transportation and carbon reduction. This research study was undertaken to determine the service quality level performance of supporting employees of the public transport as provided to the bus and train users in Klang Valley in Malaysia in effort to explore the level of quality for attracting more users. Questionnaire survey was conducted on users within two pre-determined localities in the capital city. A multi-stage approach was used where data were collected primarily through survey questionnaires. This was supported through semi-structured interviews with selected individuals and site observation of facilities provided and staff-customer interaction. Analysis of findings generally suggested that the service quality performance level generally was considered as 'average' for a number of soft trait dimensions. All these dimensions are personal interaction between the staff and the users. What emerged from the findings also suggested that there was a wide gap between service given and what is perceived and expected by the users. Such instances suggested that the service provided by the staff has yet to be considered as achieving excellent quality service level from the viewpoint of the users. As such, considerable improvement was needed to enhance the attitudes and behaviors of the staff to a level of service that would certainly satisfy and delight the users.
\end{abstract}

Keywords: Service quality, Users perceptions, Performance level, Public transport, Klang Valley, Malaysia.

Received: 2 January 2013/ Revised: 17 July 2013/ Accepted: 19 July 2013/ Published: 22 July 2013

\section{INTRODUCTION}

Improving the quality and efficiency of public transport in the country has been a major concern of the Malaysian government in order to change the daily transport habits of the public. Traffic congestion as well as environmental concerns in terms of reducing carbon footprints are 
pushing the government to provide a more reliable and dependable mode of transport for millions of public commuters in the Klang Valley. Needless to say, gaining public confidence would require an ever more personalized attention to the needs and desires of the customers, to know and quantify the most influential variables on their decision to travel in public transport (Dell'Olio et al., 2011). Lauren et al. (2013) stress that quality public transport would certainly attract private car user, thus will reduce the problem of congestion and poor air quality in the city.

As Malaysia is gearing towards becoming a developed nation by the year 2020, and has actively pledge to reduce the nation carbon emission, it is imperative to support the aspiration for a high quality public transport service.

The measurement of service quality continues to be a challenging research and remain as one of the great practical importance to public service providers in the Klang Valley. It is vital that these service providers have a good understanding on what exactly the customers want and delivers the service quality perceived by them. What is critical for these service providers is to provide the highest standard of service excellence that not only satisfies the customers or users, but more important, delighting them and ensuring that these mode of public transports remain to be the most priority means of commuting for the majority of urban population.

Hence, this study was undertaken to evaluate the extent of the users' perceptions toward the service quality level provided by the public transport providers. Ultimately, this research study is to assess the predetermined set of personality attributes and identifying their level from the viewpoint of the users' perceptions. The overall satisfaction associated with quality service performance level of staff attributes and physical facilities will also be measured.

\section{LITERATURE REVIEW}

Research evidently shows that service quality leads to customer loyalty and attraction of the new customers, positive word-of-mouth, employee satisfaction and commitment, enhance corporate image, reduced costs, and increased business performance (Berry et al., 1990). Some studies have revealed the positive relationship between perceived quality and an organization's financial performance (Dell'Olio et al., 2011; Eboli and Mazzulla, 2011), (Carse, 2011). The Service Quality Index (SQI) measures passenger's perceptions of service using a combination of RP and SP (Stated Preference) data, a process commonly used in transport research (Carse, 2011). A study by (Rohana et al., 2012) on Public Transport in the Klang Valley suggests that customers' expectations on Public Transport services were based generally on the account of safety and there are positive significant relationships between customer satisfactions, environment and loyalty, as well as positive significant relationship between environmental concern and loyalty. However, this study attempts to look from another aspect of customer perception on service providers.

According to Dell'Olio et al. (2011) a study on desired quality gives more in-depth information about their customers and what they want from the service and this form a basis for 
the service organization to develop more acceptable policies. The need to seek the users' or customers' perception is vital as they are the main actors who determine the transport service performance Eboli and Mazzulla (2011) and customers are 'the sole judge of service quality' (Berry et al., 1990). Fielding (1987) wrote that measures to define transit performance include efficiency, effectiveness, impact, productivity, and service quality. One of the methods used in this study is to gauge customers' or users' experience while using the services as experiences during travel have been shown to influence public transport customers' evaluations of the service, expectations, and the memory of frequently experienced incidents have an impact on customers' service experiences with the public transport offering (Friman et al., 2011; Olsson et al., 2012). This study was undertaken to achieve the following objectives:

(1) To find out whether users' perception of the "desired quality" as provided by the staff of transportation service provider actually met their (the users') expectation

(2) To determine the extent of the staff service quality level and ranking them according to users' perception

\section{METHODOLOGY}

The method developed for this paper is intended to provide a much-needed understanding of transport users' preference for particular modes in particular areas. To conduct this research project, the researchers deploy the SERVQUAL instrument and the Service Quality Index (SQI) including other critical factors deemed important in measuring perceptions and expectations of passengers on the level of service quality. SQI was combined with Customer Satisfaction Survey (CSS) to extract meaningful information from customers or users. A number of foreseeable factors are such as "traveling time", "helpfulness", "competency", "comfort/smoothness of journey", "drivers' attitude", cleanliness on board”, "waiting time" "punctuality”, "reliability", "safety” etc.

The SERVQUAL variables to be used are namely: "tangibles - physical facilities, equipment, station appearance and staff appearance; "responsiveness/helpfulness" - willingness to help customers, competency and provide prompt service; "friendliness" - knowledge and courtesy of employees and their capabilities; "empathy/politeness" - caring, individualized attention the company provides to its customers; "intangibles" - waiting time, travelling time punctuality, reliability and safety.

These variables were selected and used in the survey questionnaire as the focus to determine the service quality of the transport provider in this research. The use of determining the key factors in this study is to ascertain any actual or perceived gaps between users' perception and expectation of the service offered by the service providers.

To undertake this research, a "triangulation method" was used where quantitative technique will be supported by qualitative instruments. A self-administered questionnaire was used in this study to analyse the service quality expectation and perception of the public transport users. Users were asked to rate the attributes on a five-point Likert scale from (1) "very low" to (5) "very 
high". Prior to the actual fieldwork, a pilot test was undertaken to assess the reliability of the attributes and public understanding on the wordings of the questionnaires to ensure they are clear and easily understood. Reliability analysis was applied to test the internal consistency of each of the expectation and perception attributes. To measure the reliability of the questions, Cronbach Alpha test was used. Cronbach Alpha is a reliability coefficient that indicates how well the items are positively correlated to one another. It is computed in terms of the average inter correlations among the items measuring the concept.

Apart from survey questionnaires, semi-structured interviews was carried out with a total of 20 randomly selected respondents for both train and bus services. The findings from interviews actually provide evidence and support to the survey result. Another research instrument deployed were the observation of facilities provided and non-participant observation of the staffcustomer interaction. The researchers recorded the findings from first-hand observation from both designated sampling areas. These observations were video-taped and recorded and also form part of the research analysis.

\subsection{Sampling Strategy}

This research project focused on two pre-identified location of study in the Klang Valley, namely, the Masjid Jamek and Cheras/Kajang areas. A total of 3,005 set of questionnaires was distributed equally to the train (1500) and bus (1505) users during weekdays and weekends as well as during peak hours and non-peak hours. The sample design used was a multistage sample where sample routes of buses and trains during peak and off-peak time were recorded. Peak time was sampled more heavily than the off-peak time, with 2,000 survey during the peak time (6:30am - 10:30am/ 4:00pm-7:00pm weekdays) and 1,000 the off-peak time (11:00am - 3:00pm weekdays and whole day weekends). In addition to the survey questionnaires, semi-structured interview was deployed. Interviews were conducted with a total of 20 randomly selected respondents. Some of the survey and interviews were conducted in the journey as it is difficult to get respondents cooperation once they have reached their destinations.

\subsection{Reliability of Measure}

Cronbach Alpha is a reliability coefficient that indicates how items in a set are positively correlated to one another. Cronbach Alpha is computed in terms of the average correlations among the items measuring the concept. The closer the reading of Cronbach Alpha is to 1.00, the higher the internal consistency reliability. In general, reliabilities less than 0.60 are considered to be poor, those in the 0.70 range, acceptable and those over 0.80 good.

Questions in the questionnaire were group into 3: users' perception on the service quality of staff (20); users' perception on facilities (8) and users' perception on the overall performance level (3). 
Table-1.Cronbach Alpha Value of Variables

\begin{tabular}{llll}
\hline No. & Variables & No. of Items & Cronbach Alpha \\
\hline 1. & $\begin{array}{l}\text { Users Perception on Staff Service Quality } \\
\text { Level }\end{array}$ & 20 & 0.946 \\
\hline 2. & Users Perception on Physical facilities & 8 & 0.855 \\
\hline 3. & Overall Performance Level & 3 & 0.844 \\
\hline
\end{tabular}

The results from analysis indicated that the Cronbach Alpha value for the 20 items on staff service quality level measured was 0.946. For the physical facilities, the value for the 8 items measured was 0.855 . While overall performance level has 3 items and the value measured was 0.844. This suggested that the internal reliability in this study was highly acceptable and signified to be good as all the items scored over 0.80 .

\section{RESULTS AND DISCUSSION}

\subsection{Composition of Respondent's background: Gender, ethnic, age, occupation}

One of the focuses of this study is to ascertain whether users' different background may yield different expectations on the service needed. Many works (Dell'Olio et al., 2011; Eboli and Mazzulla, 2011) point to heterogeneity of passengers' perception of different aspects of the service. The heterogeneity is due to the qualitative nature of certain aspects of the services, the different attitudes passengers have towards the use of Public Transport, the different ways of viewing aspects of the service, and the social and economic characteristics of passengers and their preferences (Eboli and Mazzulla, 2011). It has even been shown that the same person may change his or her evaluation if they are made to reflect on certain important aspects of the service (Dell'Olio et al., 2011). Therefore, this research attempt to gain the widest range of passengers, consist of different background in term of gender, age, ethnicity, occupation and income. As shown in Table 2, a total of 3,005 respondents participated in the survey. Analysis of data indicated that from that total, $65 \%$ or 1,954 were female while 1051 or $35 \%$ were male. What can be concluded from this findings showed that majority of the public transport users were female.

Table-2.Breakdown of Respondents' Gender

\begin{tabular}{llll}
\hline Transportation mode & Male & Female & Total \\
\hline Bus & 472 & 1033 & 1505 \\
\hline Train & 579 & 921 & 1500 \\
\hline Total & $1051(35 \%)$ & $1954(65 \%)$ & $3005(100 \%)$ \\
\hline
\end{tabular}


Table-3.Breakdown of Age Group for Bus and Train Users

\begin{tabular}{ll|l|l|l|l}
\hline & \multicolumn{2}{l|}{ Bus } & \multicolumn{2}{l}{ Train } \\
\cline { 5 - 6 } & Frequency & Percent & Frequency & Percent \\
\hline 1 & Less than 17 year old & 152 & 10.1 & 55 & 3.7 \\
\hline 3 & $18-24$ year old & 441 & 29.3 & 564 & 37.6 \\
\hline 4 & $35-44$ year old & 391 & 26.0 & 632 & 42.2 \\
\hline 5 & $45-64$ year old & 261 & 17.3 & 169 & 11.3 \\
\hline 6 & 65 year old and above & 217 & 14.4 & 75 & 5.0 \\
\hline & Total & 43 & 2.9 & 5 & .3 \\
\hline
\end{tabular}

About age group, $72 \%$ or majority of the respondents of bus users were between $18-44$ years of age. Referring to Table 3, the total number of users from these categories actually made up a total of 1,093 from 1,500 respondents. Only $15 \%$ of the respondents fell in the age of 45 years and above. What can be concluded from this study was that, young and working adults represented the biggest portion of the bus users as compared to senior or veteran citizens who only represented a small percentage.

As for train users, the biggest age group recorded was between 18 to 34 and these groups constituted to almost $80 \%$ of total respondents as shown in Table above. For the age group of 45 and above, bus users were about $17 \%$ while train users were about $5.3 \%$. What can be concluded from this analysis suggested that most of the train users were found to be young working adults. From interview and observation, it was found that those at older age usually use the transport during non-peak hour to avoid crowd, and they prefer bus than train as it requires short walking distance to their destination and does not need rushing. In short, for both cases of bus and train, majority of users were young female working adults. They dominated the public transport in the Klang Valley and used the services almost daily for the purpose of commuting to work during weekdays.

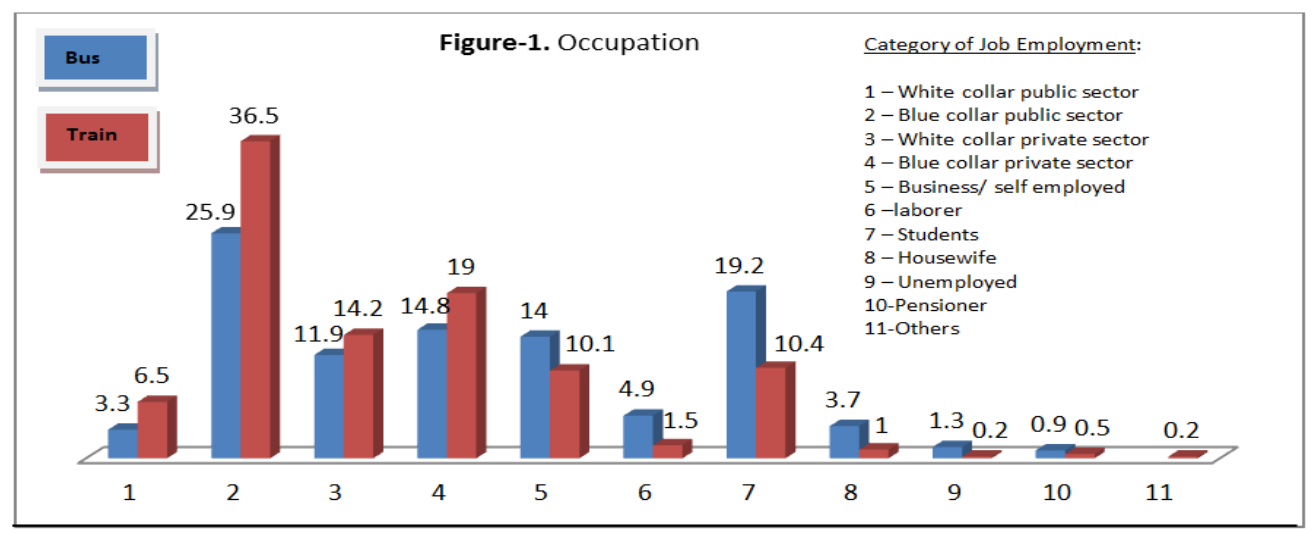


In terms of job occupation, analysis of findings showed in Figure 1 indicated that nearly $26 \%$ of the bus users were blue collar employees from the public sector. Another 19\% were students followed by blue collar workers from the private sector about $15 \%$. Together, these three major categories make up about $60 \%$ and formed majority of the bus users.

As for train users, analysis of findings in Figure 1 showed that majority or nearly $56 \%$ of the respondents were in the categories of blue collar jobs from both the public $(36.5 \%)$ and private sector $(19 \%)$. This was followed by the white collar workers from the private sector that makes up another 19 percent. Hence, it can be said that those most frequent users who commute by train were actually blue collar workers (56\%) who were either work in the public or the private sector and the white collar employees of the private sector $(19 \%)$. Together these groups formed a majority of $75 \%$ of the total train passengers.

On the overall, it can be concluded that majority of the train and bus passengers were in fact blue collar female workers who work either in the public or the private sector. This indicated that females were the frequent users of the public transport in the Klang Valley.

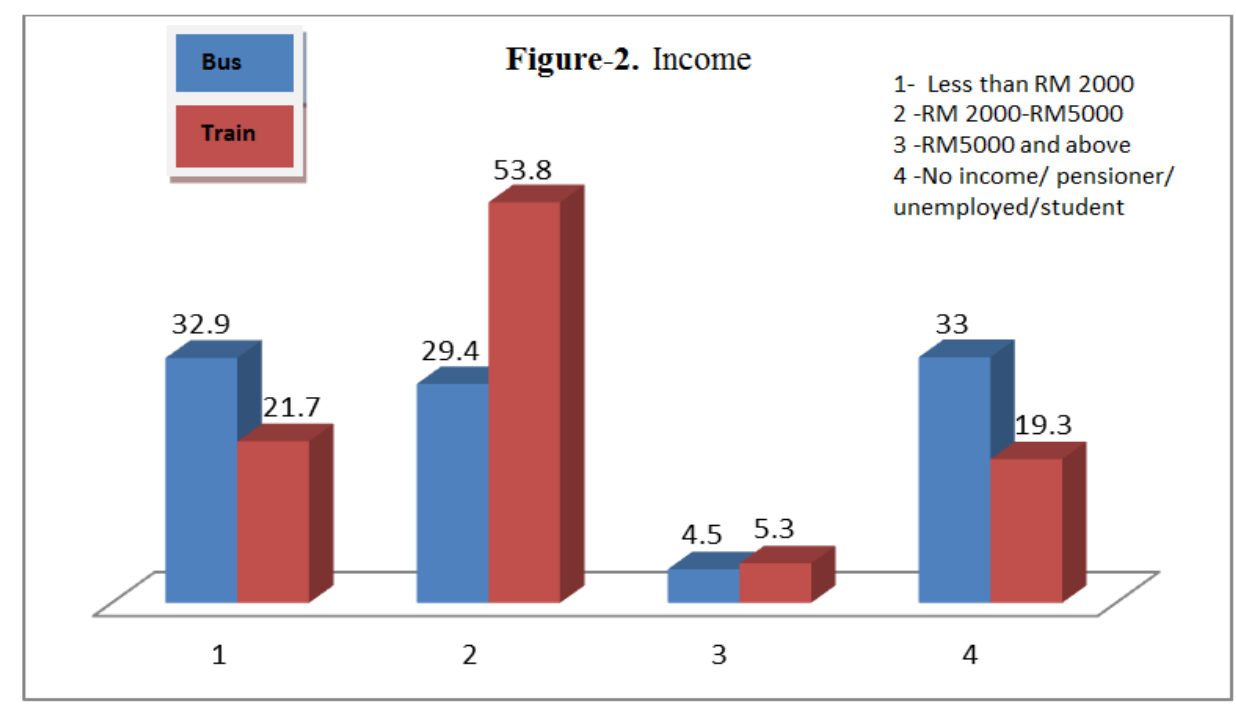

Regarding Income grouping, Figure 2 showed that from the total respondents of bus users surveyed, nearly $33 \%$ of them were earning a salary of RM2,000 per month or less. While another $29.4 \%$ were earning between RM2,000 and RM5,000 monthly. Thus, the combination of these two income group revealed that majority or $62 \%$ of the daily bus users were earning less than or equal to RM5,000 per month. What surfaced from this analysis suggested that most of the bus users were average to low income earners.

For the train users, a big portion or nearly $54 \%$ of them were earning between RM2,000 to RM5,000 per month. While another $22 \%$ of the respondents said they earned less than RM2,000 per month. What surfaced from this analysis suggested that almost $76 \%$ or majority of those who used the train services were earning RM5,000 and less. Interviews revealed that majority of 
young adults were quite new in the workforce and confessed that they would like to own transport if they can afford it and they may not use the public transport if they have other choices.

\subsection{Analysis on Staff Service Quality Performance Level}

This section discussed on the service quality of the staff for both bus and train services. Several soft skills of the human traits were evaluated by a total of 3,005 respondents. The dimensions considered include staff politeness, level of knowledge, friendliness, competency and helpfulness.

Table-4.Users' Perception on Staff Service Quality

\begin{tabular}{lccccc}
\hline Staff & Politeness & Helpfulness & Friendliness & Knowledgeable & Competency \\
\hline CSA & 3.41 & 3.60 & 3.28 & 3.71 & 3.35 \\
\hline $\begin{array}{l}\text { Security } \\
\text { Guard }\end{array}$ & 3.44 & 3.41 & 3.39 & 3.63 & 3.40 \\
\hline $\begin{array}{l}\text { Station } \\
\text { Master }\end{array}$ & 3.58 & 3.46 & 3.43 & 3.62 & 3.46 \\
\hline
\end{tabular}

As can be seen from Table 4, on the overall, majority of the users said that the staff was polite (mean from 3.41 to 3.58) from a scale of 5.00. Majority of the respondents felt that the Customer Service Assistants (CSA) were 'knowledgeable', (mean=3.71) and they were also satisfied with the staff in providing information. In other words, the respondents generally agreed that the CSA were seen a source of well-informed individuals. Of all the items, 'friendliness' seem to score the lowest. From interview, some respondents indicated that they were dissatisfied with the CSAs' attitude that does not have eye contact and lack of smile when communicating. One respondent noticed that some staff may be very helpful during morning hours but due to long working hours, they seemed to be not 'helpful' or 'friendly' in the late afternoon due to fatigue.

Analysis of results as depicted in Table 4 indicated that the overall service quality performance level for items 'politeness', 'knowledgeable', 'helpfulness', 'friendliness' and 'competency' indicated "average to good" score value (mean=3.28 to 3.71) by majority of the respondents.

In conclusion, what surfaced from this finding indicated that on a general account, the quality service provided by the staff can be said to be good except for 'friendliness'. This also indicated that generally respondents felt that the role of the staff was not up to the level as expected as none of the scores were up to even 4.0. In short, the survey analysis indicated that almost all items evaluated showed an average to low performance level. Hence, immediate improvement through training intervention is seen as imperative in order for the organization to enhance the service quality level of their staff. 


\subsection{Facilities at Transportation Hub}

There is undeniable that facilities provided would influence users' perception on quality service. Overall, rating for facilities at bus hub received lower scores than train hubs as depicted in Table 5. This is because such facilities measured at the selected terminals were old and not under the transport service providers' care. Observation confirmed these findings, as some of the hubs as there were no safety precaution for users from incoming traffic, poorly lit station and heavily polluted from emission from idle buses.

Table-5.Users Satisfaction on Provided Facilities at Bus Hub and Train Station

\begin{tabular}{lcllc}
\hline Facilities & Seating & Cleanliness & Handicapped & $\begin{array}{c}\text { Ticket } \\
\text { System }\end{array}$ \\
\hline Bus Hub & 2.59 & 2.52 & 2.48 & nil \\
\hline Train Station & 3.90 & 3.79 & 3.95 & 3.79 \\
\hline
\end{tabular}

There were complaints on ticketing system due to long queue to purchase tickets, which was confirmed from observations. The providers insisted, from interviews, that they were in the process of educating the Malaysian public and providing awareness and arranging some special rewards to motivate more passengers to purchase travel cards to ease the problems. It is welcoming to find that toilet has received quite high rating along with escalator, which means majority of respondents are satisfied with the facilities. However, majority complaints received were on the cleanliness and unclear signage to guide users to designated platforms and schedule of the trips. Table 6 below explores detail responds that indicate signage get the lowest score of 3.45 .

Table-6.Users Satisfaction on some Facilities Provided

\begin{tabular}{lllllllll}
\hline Item & Escalator & $\begin{array}{l}\text { Toile } \\
\mathbf{t}\end{array}$ & Lift & $\begin{array}{l}\text { Signag } \\
\mathbf{e}\end{array}$ & $\begin{array}{l}\text { Disable } \\
\text { Facility }\end{array}$ & $\begin{array}{l}\text { Automatic } \\
\text { Gate }\end{array}$ & PA System & $\begin{array}{l}\text { Safety and } \\
\text { Security }\end{array}$ \\
\hline Mean & 3.63 & 3.63 & 3.57 & 3.45 & 3.56 & 3.59 & 3.50 & 3.50 \\
\hline
\end{tabular}

Exploring quality service includes getting feedback on intangible services such as punctuality and safety as shown in Table 7. It was revealed that punctuality received the lowest score of 3.07 although majority of respondents agree that the public transportation are comfortable (3.68) and safe (3.67). The issue of punctuality has been raised by respondents during interview as one major deterrent for them to continue using the service as well as to attract new users as reliability for them to arrive on time to workplace and home are very crucial. 
Table-7.Users Satisfaction on Intangible Service Items

\begin{tabular}{lllllll}
\hline Items & Punctuality & Comfort & Safety & $\begin{array}{l}\text { Bus Stop at } \\
\text { Designated Place }\end{array}$ & $\begin{array}{l}\text { Driver } \\
\text { Honesty }\end{array}$ \\
\hline Mean & 3.07 & 3.68 & 3.67 & 3.41 & 3.35 \\
\hline
\end{tabular}

This study also attempts to explore whether there are differences in perception of different genders. Analysis of data reveals that there is not much difference between users' satisfaction according to gender as shown in Figure 3. Percentage of male respondents that give rating 4 and 5 is $85.1 \%$ while the female counterpart is $85.2 \%$. Almost similar percentage is shown for the excellent vote of 5 where $7 \%$ of male and only $6.5 \%$ of female give the highest rating. Interviews revealed that majority of respondents were moderately satisfied with the service but they insisted that Malaysian Public Transport still need a lot of improvements to become excellent.

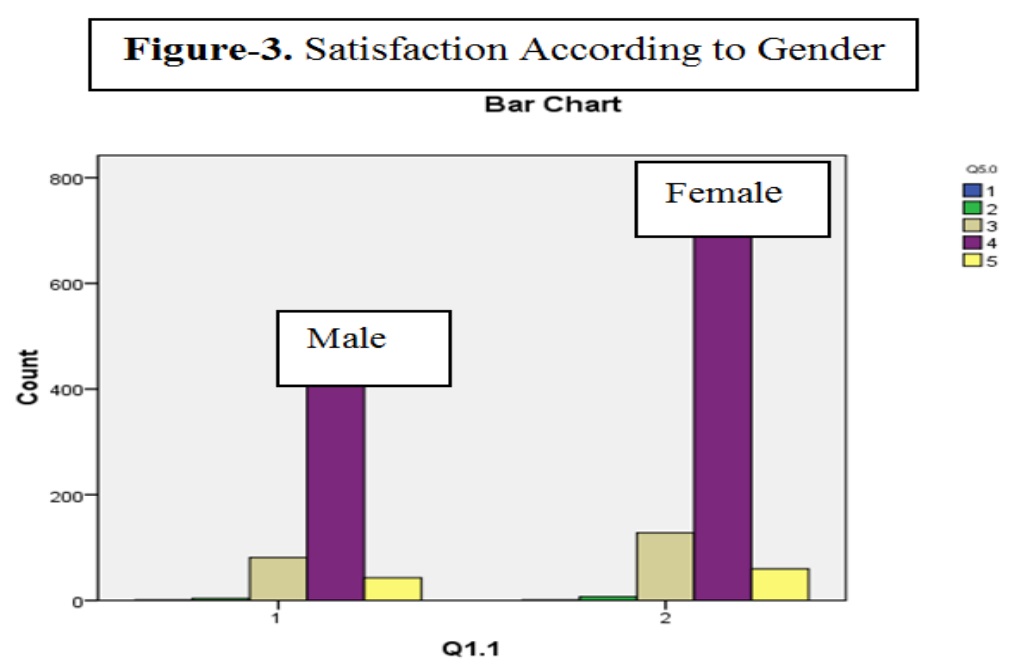

Analysis of data on user satisfaction based on the income level shows that those income of more than RM5000 are more critical and demanding as only $75 \%$ of them give 4 and 5 ranking. Other groups show almost similar response where those earned less than RM2000 (84\%), those within RM2000-RM5000 (85\%) while $86 \%$ of those who are not working or retired give 4 and 5 ranking. However, the lowest ranking were given by these 3 groups where 2 people give ranking 1 and 11 give ranking 2 . 
Figure-4. User Satisfaction according to income

Bar Chart

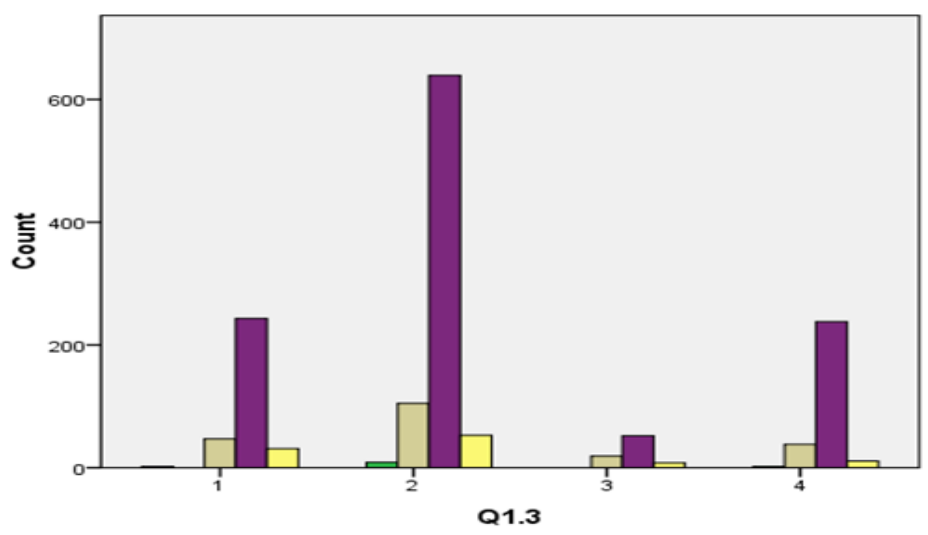

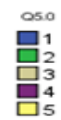

Figure 5 summed up the research by tabulating the overall users' satisfaction and perception on the quality service of the public transport. Train users give high ratings where $78.3 \%$ given rate 4 and $6.9 \%$ gave the score 5 o their satisfaction of the service. On the other hand, the bus services received lower percentage of respondents that gave the score $4(44.9 \%)$ but a reasonable percentage $(22.5 \%)$ were satisfied with the service.

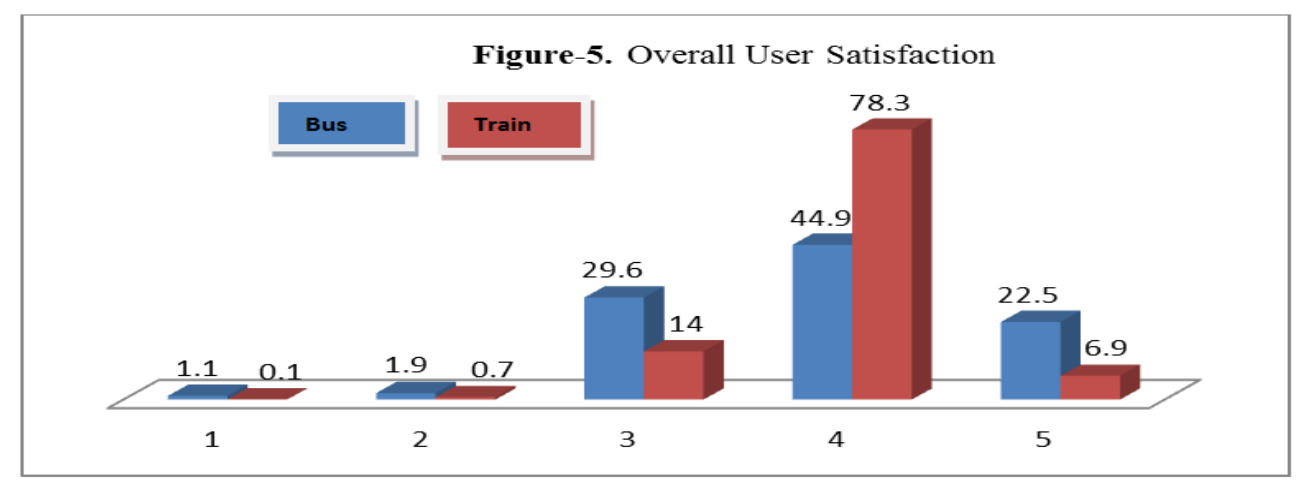

\section{CONCLUSION}

In summary, it can be said that the service quality performance level as provided by the Public Transport staff perceived by users in the Klang Valley, Malaysia, as moderate and staff were perceived as "average performers". What surfaced from these findings suggested that there is a wide gap between what is perceived quality service by providers with what is expected from the viewpoint of the users. Hence, much effort is needed to improve the situation and in particular, by providing staff training and education. There were not much difference in users' opinion based on gender, however those within higher income bracket tend to be more critical compared to those with less than RM 2000 monthly income. Some good suggestions surfaced from this study are the willingness of the providers to upgrade their service in term of educating their staff and users. In addition, it is suggested that Stations/public transport interchanges should preferably be located 
within a walking distance of 500 meters or 10 to 15 minutes walk from major housing, employment, shopping, commercial, cultural and other population intensive activity centres with properly planned pedestrian walkway systems and adequate parking to improve connectivity. Good signage and improved ticketing systems not only will assist smooth rides but also ease the burden of staff to manage passengers. This will help to promote usage of public transport services, to ease road congestion by alleviating the reliance on private vehicles and to assist Malaysia to reach the level of world class public transportation service.

Funding: This study received no specific financial support.

Competing Interests: The authors declare that they have no competing interests.

Contributors/Acknowledgement: All authors contributed equally to the conception and design of the study.

\section{REFERENCES}

Berry, L., A. Zeithaml and A. Parasuraman, 1990. Five imperatives for improving service quality. Sloan Management Review, 29(Summer): 9-38.

Carse, A., 2011. Assessment of transport quality of life as an alternative transport appraisal technique. Journal of Transport Geography, 19(5): 1037-1045.

Dell'Olio, L., A. Ibeas and P. Cecin, 2011. The quality of service desired by public transport users. Transport Policy, 18(1): 217-227.

Eboli, L. and G. Mazzulla, 2011. A methodology for evaluating transit service quality based on subjective and objective measures from the passenger's point of view. Transport Policy, 18(1): 172-181.

Fielding, J., 1987. Managing public transit strategically: A comprehensive approach to strengthening service and monitoring performance. San Francisco: Jossey-Bass Publishers.

Friman, M., B. Edvardsson and T. Garling, 2011. Frequency of negative critical "incidents and satisfaction with public transport services i. Journal of Retailing and Consumer Services, 8(2): 95-104.

Lauren, R., F. Margareta, G. Tommy and H. Terry, 2013. Quality attributes of public transport that attract car users. Transport Policy, 25(1): 119-127.

Olsson, L., E. , F. Margareta, P. Jörg and B. Edvardsson, 2012. Measuring service experience: Applying the satisfaction with travel scale in public transport Journal of Retailing and Consumer Services, $19(4): 413-418$.

Rohana, K., O. Ismah and C.P. Che Anizaliana, 2012. Public transport services in klang valley: Customer expectations and its relationship using sem. Procedia - Social and Behavioral Sciences, 36(1): 431438.

http://www.pland.gov.hk/pland_en/tech_doc/hkpsg/full/ch8/ch8_text.htm\#1. 